\title{
Avoiding the under-diagnosis of low bone mineral density in Egyptian children with chronic medical conditions affecting bone health
}

\author{
Nagwa Abdallah Ismail \\ Paediatrics Department, National Research Centre, Cairo, Egypt \\ Corresponding author: \\ Submitted: 20 September 2010 \\ Accepted: 7 December 2010 \\ Arch Med Sci 2011; 7, 4: 700-705 \\ DOI: 10.5114/aoms.2011.24142 \\ Copyright @ 2011 Termedia \& Banach \\ Prof. Nagwa Abdallah Ismail \\ Paediatrics Department, \\ National Research Centre \\ Albhoss Street \\ Cairo, Egypt \\ E-mail: nagwa_abdallah@ \\ yahoo.com
}

\begin{abstract}
Introduction: The International Society for Clinical Densitometry recommended that the lumbar spine and total body less head (TBLH) are the most accurate and reproducible skeletal sites for performing areal bone mineral density (BMD) measurements. Our objective is to evaluate the role of measurement of femoral neck BMD in avoiding the under-diagnosis of low BMD being a risk for fractures in subjects with chronic medical conditions that might affect bone health.

Material and methods: Subjects with chronic medical conditions that might affect bone health were studied $(n=468)$ and 36 healthy children were recruited as control subjects. Physical examinations, height, weight measurements and $\mathrm{BMI}$ were calculated. Dual-energy radiographic absorptiometry of the lumbar spine and femoral neck were measured.

Results: Bone mineral density $z$ scores in both sites were significantly reduced in chronic patients, compared with control subjects. Prevalence of very low BMD $z$ scores ( -2 or more) using lumbar DXA, femoral DXA, and either of the sites were $1.38 \%, 3.37 \%$, and $3.96 \%$, respectively, while low BMD $Z$ scores ( -1 to less than -2 ) were $9.52 \%, 18.05 \%$ and $21.14 \%$ respectively.

Conclusions: We identified a significant decrease in both lumbar and femoral BMDs in studied children. Sometimes femoral BMD is decreased while lumbar $B M D$ is still within the normal range. For this reason we recommend that, when technically feasible and there is no facility to measure TBLH, all those patients should have lumbar spine and femoral neck bone mineral density measurements to avoid under-diagnosis of low BMD being a risk for fractures.
\end{abstract}

Key words: osteoporosis, bone density, chronic diseases.

\section{Introduction}

Bone health in children is increasingly recognised in paediatric practice. Low bone mineral density (BMD) can result from a wide variety of childhood diseases and the treatments [1, 2]. The classical definition of osteoporosis should be valid at any age, yet its practical applicability to children and adolescents remains a matter of debate and there is no consensus on a diagnosis based solely on the BMD value. The clinical relevance of uncomplicated low bone density in the young and its long-term consequences remain difficult to evaluate and there is only preliminary evidence that the BMD value is a predictor of fracture risk in growing subjects [3]. 
Moreover, the interpretation of densitometric data in the young is difficult because the "normal" BMD values to be used for comparison are continuously changing with age, and in addition depend on several variables, such as gender, body size, pubertal stage, skeletal maturation and ethnicity. Most methods to adjust bone mineral content (BMC)/BMD Z-scores for height were biased by age and/or height for age $Z$ score (HAZ). Adjustments using HAZ were least biased relative to $\mathrm{HAZ}$ and age and can be used to evaluate the effect of short or tall stature on BMC/BMD Z-scores [4]. Although Z-score values below -2 are generally considered a serious warning, most bone specialists make a diagnosis of osteoporosis in children and adolescents only in the presence of low BMD and at least one fragility fracture [5].

Dual energy X-ray absorptiometry (DXA) is considered the gold standard of BMD measurement. The International Society for Clinical Densitometry Official Positions recommended that the lumbar spine and total body less head (TBLH) are the most accurate and reproducible skeletal sites for performing BMC and areal BMD measurements [6].

The aim of this study is to evaluate the role of measurement of femoral neck BMD in avoiding the under-diagnosis of low bone mineral density being a risk for fractures in subjects with chronic medical conditions that might affect bone health.

\section{Material and methods}

\section{Study design}

A total of 700 patients were referred to the Pediatric Clinic at the National Research Centre (NRC) in the period from March 2005 to March 2009; of these 468 patients were included. Thirty-six healthy age- and sex-matched children were also included in the study, serving as a control group.

\section{Inclusion criteria}

Age 5 years or more because the femoral neck may be too small for the standard software and changing its shape makes studies difficult and unreliable for younger children.

\section{Exclusion criteria}

- Children with conditions preventing or limiting the use of standard measurement sites or positioning for densitometry evaluation such as scoliosis, or altered body postures or muscular contractures that prevent them from lying flat in a supine position for optimal measurement of the spine or hip.

- Artefacts and abnormalities in spinal vertebra.

- Parents refused inclusion in the study.
So the study was conducted on 504 subjects including 36 healthy controls and 468 patients with chronic diseases: bronchial asthma, diabetes mellitus, congenital adrenal hyperplasia, chronic renal failure, nephrotic syndrome, chronic liver diseases, coeliac disease, juvenile rheumatoid arthritis (JRA), mucopolysacharidosis, hypothyroidism, chronic haemolytic anaemia, and phenylketonuria (Table I).

\section{Methods}

Informed consent was obtained from the parents of the children according to guidelines of the ethical committee of NRC, Dokki, Egypt. All patients were subjected to full history taking and general examination.

\section{Anthropometric measurements}

Anthropometric measurements (height and weight) were measured. Weight was measured using a standard clinical balance (weight was approximated to the nearest $0.1 \mathrm{~kg}$ ) and height was measured using a fixed stadiometer (height was approximated to the nearest millimetre). All measurements were made with the children wearing light indoor clothes without their shoes.

Body mass index (BMI) was calculated as weight divided by height squared $\left(\mathrm{kg} / \mathrm{m}^{2}\right)$. Pubertal status was determined and classified according to Tanner stages as prepubertal (stage I), early puberty (stages $\mathrm{II}$ and III) and late puberty (stages IV and V) [7].

\section{Bone mineral measurements}

Bone mineral measurements were done using dual energy X-ray absorptiometry (DXA) (Norland -

Table I. Diagnosis of the studied group

\begin{tabular}{|lc|}
\hline Cases & No. \\
\hline Coeliac disease & 25 \\
\hline Chronic liver disease & 25 \\
\hline Bronchial asthma & 80 \\
\hline Chronic renal failure & 65 \\
\hline Chronic Hm anaemia & 30 \\
\hline Juvenile rheumatoid arthritis (JRA) & 30 \\
\hline Suprarenal hyperplasia & 30 \\
\hline Thyroid diseases & 35 \\
\hline Metabolic disorders & 50 \\
\hline Nephrotic Pts treated with corticosteroids & 30 \\
\hline Type 1 diabetes & 35 \\
\hline Phenylketonuria & 25 \\
\hline Mucopolysacharidosis & 8 \\
\hline Control & 36 \\
\hline Total & 504 \\
\hline
\end{tabular}


XR-46, USA). Bone mineral density of the lumbar spine (L1-L4) and Lt femoral neck were performed at the Medical Services' Centre, NRC. Absolute values were converted to $Z$-scores. Bone mineral density was expressed in $\mathrm{g} / \mathrm{cm}^{2}$ [8]. Height-for-age $Z$-score (HAZ) and age were used to adjust the effect of short or tall stature on BMD Z-scores [4].

\section{Statistical analysis}

Statistical Package for Social Sciences (SPSS) program version 12 was used for analysis of data. Data were described in terms of mean \pm SD and percentage. Analysis of two quantitative independent variables was done by using a non-parametric test (Mann-Whitney $U$ test) and $\chi^{2}$ test was used

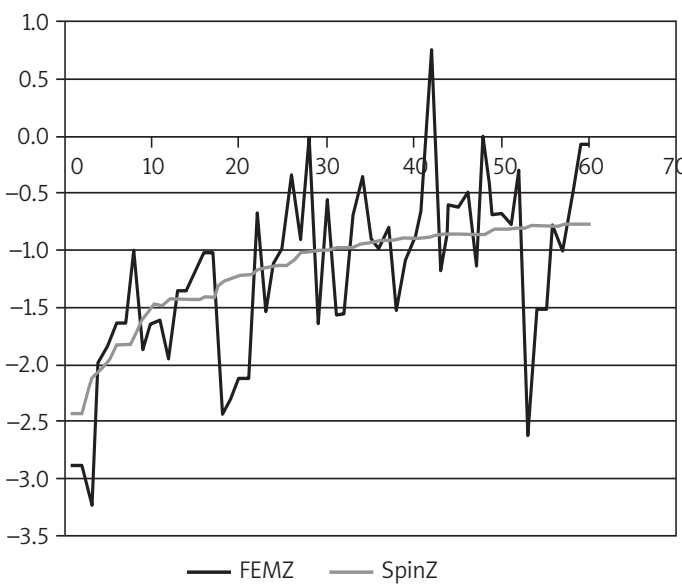

Figure 1. Relation between femoral and spinal BMD scores in a subgroup including 60 patients for qualitative variables. Spearman correlation was done. Value of $p$ is considered significant if $<0.05$

\section{Results}

We studied 468 patients (266 female and 202 male) with different types of chronic diseases (Table I) whose mean age was $9.69 \pm 4.46$ years, and 36 healthy controls ( 21 females and 15 males) whose mean age was $10.07 \pm 4.36$ years Characteristics of patients and controls are summarized in Table II. Duration of disease ranged from 1 to 12 years. Dual energy X-ray absorptiometry measurements demonstrate that BMD of the femoral neck and lumbar sites were significantly lower in chronic patients than in the control group ( $p=0.005$ and $p=0.001$ respectively).

Prevalence of very low BMD ( -2 or less) using femoral neck DXA, lumbar DXA and either of the sites was $3.37 \%, 1.38 \%$, and $3.95 \%$, respectively, while low BMD (between -1 and -2) using femoral neck DXA, lumbar DXA, and either of the sites was $18.05 \%, 9.52 \%$, and $22.02 \%$ respectively, as shown in Table III. Figure 1 shows the relation between femoral and spinal BMD scores in a subgroup including 60 patients. It also shows that femoral $B M D$ could be reduced while spinal BMD is still within the normal range. Table IV shows the correlations between BMD and anthropometry in the studied group.

Fracture rates as high as $13.3 \%$ have been reported in the juvenile rheumatoid arthritis (JRA) group. The frequency of low BMD ( $Z$ score $<-1$ SD) at the level of the femoral neck was significantly

Table II. Characteristics of the patients and controls

\begin{tabular}{|c|c|c|c|c|c|c|}
\hline Parameters & $\begin{array}{c}1 \text { = case } \\
2 \text { = control }\end{array}$ & $N$ & Mean & $\begin{array}{l}\text { Standard } \\
\text { deviation }\end{array}$ & $\begin{array}{l}\text { Standard } \\
\text { error mean }\end{array}$ & Value of $p$ \\
\hline \multirow[t]{2}{*}{ Age } & Case & 468 & 9.6980 & 4.46 & 0.22 & 0.49 \\
\hline & Control & 36 & 10.0759 & 4.36 & 0.49 & \\
\hline \multirow[t]{2}{*}{ Femoral neck BMD } & Case & 468 & -0.4997 & 0.77 & 0.03 & $0.005^{\star}$ \\
\hline & Control & 36 & -0.2970 & 0.53 & 0.06 & \\
\hline \multirow[t]{2}{*}{ Spine BMD } & Case & 468 & -0.2536 & 0.85 & 0.04 & $0.001^{*}$ \\
\hline & Control & 36 & 0.0814 & 0.72 & 0.08 & \\
\hline
\end{tabular}

*value of $p$ is statistically significant

Table III. Percentage distribution of BMD Z scores in the studied group

\begin{tabular}{|lcccccccccc|}
\hline \multirow{2}{*}{ Item } & \multicolumn{2}{c}{$\begin{array}{c}\text { Femoral Z } \\
\text { All cases }\end{array}$} & \multicolumn{2}{c}{$\begin{array}{c}\text { Spinal Z } \\
\text { All cases }\end{array}$} & \multicolumn{2}{c|}{ Both sites } & \multicolumn{2}{c|}{$\begin{array}{c}\text { Femoral alone } \\
\text { affected }\end{array}$} & \multicolumn{2}{c|}{ Spine alone } \\
\cline { 2 - 12 } & No & $(\%)$ & No & $(\%)$ & No & $(\%)$ & No & $(\%)$ & No & $(\%)$ \\
\hline-2 or less & 17 & 3.37 & 7 & 1.38 & 4 & 0.79 & 13 & 2.57 & 3 & 0.59 \\
\hline Between -1 and -2 & 91 & 18.05 & 48 & 9.52 & 31 & 6.15 & 60 & 11.90 & 18 & 3.97 \\
\hline Above -1 & 396 & 78.57 & 449 & 89.08 & 323 & 64.08 & - & 0.0 & 52 & 10.31 \\
\hline Total & 504 & 100 & 504 & 100 & 358 & 71.03 & 73 & 14.48 & 73 & 14.48 \\
\hline
\end{tabular}


Table IV. Correlations between BMD and anthropometry in the studied group

\begin{tabular}{|lcccccc|}
\hline Item & & Femoral neck & Spine & HAZ & WAZ & BMI \\
\hline Femoral BMD & $\mathrm{R}$ & & $0.648^{* *}$ & 0.064 & 0.016 & -0.079 \\
\cline { 2 - 7 } & $\mathrm{P}$ & 0.000 & 0.000 & 0.206 & 0.746 & 0.118 \\
\hline Spine BMD & $\mathrm{R}$ & $0.648^{\star *}$ & & 0.106 & 0.085 & -0.087 \\
\cline { 2 - 7 } & $\mathrm{P}$ & 0.000 & 0.000 & 0.035 & 0.092 & 0.085 \\
\hline HAZ & $\mathrm{R}$ & 0.064 & 0.106 & & $0.869^{* *}$ & 0.079 \\
\cline { 2 - 7 } & $\mathrm{P}$ & 0.206 & 0.035 & 0.0 & 0.000 & 0.099 \\
\hline WAZ & $\mathrm{R}$ & 0.016 & 0.085 & $0.86^{* *}$ & & $0.485^{* *}$ \\
\cline { 2 - 7 } & $\mathrm{P}$ & 0.746 & 0.092 & 0.000 & 0.0 & 0.000 \\
\hline BMI & $\mathrm{R}$ & -0.079 & -0.087 & 0.079 & $0.485^{* *}$ & \\
\cline { 2 - 7 } & $\mathrm{P}$ & 0.118 & 0.085 & 0.099 & 0.000 & 0.0 \\
\hline
\end{tabular}

**means value is statistically significant, $R$-correlation coefficient, $P$ - probability level, HAZ - height for age Z-score, WAZ - weight for age Z-score

higher (40\%) in children with JRA than healthy children $(8 \%) \quad(p=0.013)$, and although the frequency was higher at the lumbar spine of the patients $(26.7 \%)$ vs. controls $(8 \%)$ it was not significant $(p=0.074)$, with no sex-related difference. Only 1 patient (3.3\%) was found to have very low BMD (Z score <-2 SD) in the femoral neck [9].

\section{Discussion}

The purpose of the current study was to evaluate the role of measurement of femoral neck BMD in avoiding the under-diagnosis of low BMD being a risk for fractures in subjects with chronic medical conditions that might affect bone health. In the present study, lumbar (L2-L4) and femoral neck BMD were analysed together in all cases and controls. The terms "osteopenia" and "osteoporosis" should not be used in paediatric DXA reports because they refer specifically to WHO fracture risk criteria developed for postmenopausal women. There are no similar criteria for osteoporosis based on BMD for children, adolescents, or premenopausal women [10]. Michael et al. (2008) reported that the term "osteoporosis" should not appear in paediatric DXA reports without knowledge of clinically significant fracture history [11]. Some studies found that it is reasonable to imagine that a $Z$ score of -1 or less might be suggestive of the paediatric equivalent of osteopenia and a $Z$ score of -2 or less suggestive of an osteoporosis equivalent $[10,11]$.

"Low bone mass for chronological age" is the preferred term when the BMC or BMD Z-score is less than or equal to -2.0 [12]. Although estimation of total body less head (TBLH) BMD is valuable in children, it was technically not feasible to estimate it in our study.

Our DXA results were categorized according to the following cut-off points for children: the diagnosis of very low BMD defined as a BMD of
2 SD or more below the mean value (the $Z$ score) compared to age- and sex-matched healthy controls. According to this approach, low BMD would be said to exist when the BMD $Z$ score lies between -1 and -2 SD. So our study found that about $3.69 \%$ of our children with chronic diseases had very low BMD, while low BMD between -1 SD and -2 SD were 9.52\%, $18.05 \%$ and $21.14 \%$ respectively. Also there is a correlation between the lumbar spine and femoral neck regions. Although BMDs of the lumbar spine and hip regions are strongly related in healthy children, considerable anatomical differences between the two sites may become apparent as BMD decreases [13].

The spine is formed mainly of trabecular bone, which has a higher surface-to-volume ratio and is more active metabolically than other regions of skeleton [5]. Because of the greater rapidity of bone turnover in the trabecular compartment than in the cortical one, the spine is thought to be a more sensitive site than the long bones of the upper and lower extremities for evaluating the effects of various stimuli on bone mineral status of the body $[10,14]$. Previous studies have reported that the spine, which is predominantly trabecular bone, is more sensitive to various therapeutic modalities, including methotrexate and corticosteroids, than the femoral neck, which contains more cortical bone [15-17]. Van der Sluis et al. found that children with acute lymphoblastic leukaemia Diseaseassociated changes in the quantity and distribution of cortical and cancellous bone around the femoral neck might contribute to enhance hip fragility in osteoporosis bone fragility does not only result from cortical thinning but also from trabecular bone rarefaction associated with loss of trabecular connectivity [18-20].

In other cross-sectional studies, significant reductions in both lumbar and femoral BMDs were observed in children with acute lymphoblastic 
leukemia disease (ALL) at completion of chemotherapy and in long-term survivors of childhood ALL [21-23]. The bone loss caused by immobilization could partly explain the finding of a reduction in femoral BMD in children with cancer. The loss of bone during immobilization has been found to be greater in weight-bearing bones and to be more pronounced in younger patients [24].

In cortical bone, immobilization induced bone loss has been shown to become conspicuous after 3-6 months of inactivation [24]. Pathological fractures, predominantly in the femur, and osteoporosis after immobilization have been observed in children with cerebral palsy [25]. According to our results and others [5, 26, 27] a follow-up of both lumbar and femoral BMD is required to further evaluate the development of $B M D$ in these children during their entire treatment.

Scanning the femoral neck in children, however, is difficult because the skeletal landmarks may not be well developed and the femoral neck may be too small for the standard software. These factors contribute to poorer precision in this region. Additionally, there are few paediatric reference data for this site. The femoral neck region is not recommended in very young children because its changing shape makes longitudinal studies difficult and unreliable [28, 29].

In conclusion, we identified significant reductions in both lumbar and femoral BMDs in children with chronic medical conditions that might affect bone health. For this reason we recommend that, when technically feasible and there is no facility to measure TBLH, all patients should have spine and femoral neck bone mineral density measurements to avoid under-diagnosis of low bone mineral density being a risk for fractures in subjects with chronic medical conditions that might affect bone health.

\section{References}

1. Bianchi ML Osteoporosis in children and adolescents Bone 2007; 41: 486-514.

2. Lane NE. Epidemiology, etiology, and diagnosis of osteoporosis. Am J Obstet Gynecol 2006; 194: S3-11.

3. Clark EM, Tobias JH, Ness AR. Association between bone density and fractures in children: a systematic review and meta-analysis. Pediatrics 2006; 117: 291-7.

4. Zemel BS, Leonard MB, Kelly A, et al. Height adjustment in assessing dual energy $\mathrm{X}$-ray absorptiometry measurements of bone mass and density in children. J Clin Endocrinol Metab 2010; 95: 1265-73.

5. Ward LM, Glorieux FH. The spectrum of pediatric osteoporosis. In: Glorieux FH, Pettifor JM, Jüppner H, editors. Pediatric bone: biology and diseases. San Diego, CA: Academic Press 2003; 401-42.

6. Gordon CM, Bachrach LK, Carpenter TO, et al. Dual energy $\mathrm{X}$-ray absorptiometry interpretation and reporting in children and adolescents: The 2007 ISCD Pediatric Official Positions. J Clin Densitom Assess Skeletal Health 2008; 11: 43-58.
7. Tanner JM. The development of the reproductive system. In: Growth at adolescence. 2nd ed. Blackwell Scientific Publication, Oxford 1962.

8. Zanchetta JR, Plotkin H, Alvarez Filgueira ML. Bone mass in children: normative values for the 2-20-year-old population. Bone 1995; 16 (4 Suppl): S393-9.

9. Kandil ME, Mourad A, El Hamshary A, Hussein G, Ahmed A, Mawgoud SA. Evaluation of bone mineral density and bone turnover markers in Egyptian children with juvenile rheumatoid arthritis. Arch Med Sci 2009; 5: 434-42.

10. Carter DR, Bouxsein ML, Marcus R. New approaches for interpreting projected bone densitometry data. J Bone Miner Res 1992; 7: 137-45.

11. Lewiecki EM, Gordon CM, Baim S, et al. International Society for Clinical Densitometry 2007 Adult and Pediatric Official Positions. Bone 2008; 43: 1115-21.

12. Lewiecki EM, Watts NB, McClung MR, et al. Position statement. Official positions of the International Society for Clinical Densitometry. J Clin Endocrinol Metab 2004; 89: 3651-55.

13. Bailey DA, McKay HA, Minwald RL, Crocker PRE, Faulkner RA. A six-year longitudinal study of the relationship of physical activity to bone mineral accrual in growing children: The University of Saskatchewan Bone Mineral Accrual Study. J Bone Miner Res 1999; 14: 1672-79.

14. NIH Consensus Development Panel on Osteoporosis Prevention, Diagnosis, and Therapy. Osteoporosis prevention, diagnosis, and therapy. JAMA 2001; 285: 785-95.

15. Moreira-Andrés MN, Cañizo FJ, Papapietro K, Rejas J, Hawkins FG. Comparison between spinal and radial bone mineral density in children measured by $\mathrm{x}$-ray absorptiometry. J Pediatr Endocrinol Metab 1995; 8: 35-41.

16. Wheeler DL, Vander Griend RA, Wronski TJ, Miller GJ, Keith $E E$, Graves JE. The short- and long-term effects of methotrexate on the rat skeleton. Bone 1995; 16: 215-21.

17. Gnudi S, Butturini L, Ripamonti C, Avella M, Bacci G. The effect of methotrexate (MTX) on bone. A densitometric study conducted on 59 patients with MTX administered at different doses. Ital J Orthop Traumatol 1998; 14: 227-31.

18. van der Sluis IM, van den Heuvel-Eibrink MM, Hählen K, Krenning EP, de Muinck Keizer-Schrama SM. Altered bone mineral density and body composition, and increased fracture risk in childhood acute lymphoblastic leukaemia. J Pediatr 2002; 141: 204-10.

19. van der Sluis IM, van den Heuvel-Eibrink MM, Hählen K, Krenning EP, de Muinck Keizer-Schrama SM. Bone mineral density, body composition, and height in long-term survivors of acute lymphoblastic leukemia in childhood. Med Pediatr Oncol 2000; 35: 415-20.

20. Jarfelt $M$, Fors $H$, Lannering B, Bjarnason R. Bone mineral density and bone turnover in young adult survivors of childhood acute lymphoblastic leukaemia. Eur J Endocrinol 2006; 154: 303-9.

21. Arikoski P, Komulainen J, Riikonen P, Voutilainen R, Knip M, Kroger $\mathrm{H}$. Alterations in bone turnover and impaired development of bone mineral density in newly diagnosed children with cancer: a 1-year prospective study. J Clin Endocrinol Metab 1999; 84: 3174-81.

22. Arikoski P, Komulainen J, Voutilainen R, et al. Reduced bone mineral density in long-term survivors of childhood acute lymphoblastic leukemia. J Pediatr Hematol Oncol 1998; 20: 234-40.

23. Arikoski P, Komulainen J, Riikonen P, Jurvelin J, Voutilainen $\mathrm{R}$, Kröger $\mathrm{H}$. Reduced bone density at completion of chemotherapy for a malignancy. Arch Dis Child 1999; 80: 143-8. 
24. Arikoski P, Voutilainen $\mathrm{R}$, Kroger $\mathrm{H}$. Bone mineral density in long-term survivors of childhood cancer. J Pediatr Endocrinol Metab 2003; 16: 343-53.

25. Ruiz JC, Mandel C, Garabedian M. Influence of spontaneous calcium intake and physical exercise on the vertebral and femoral bone mineral density of children and adolescent. J Bone Miner Res 1995; 1: 675-81.

26. ElBaky AA, Ismail NA, Salama E, Abou-Zekri M, Fatouh A, Ragab S. Inappropriate restriction of dietary gluten and associated bone and bone density in Egyptian Children with celiac disease. Arch Med Sci 2009; 5: 589-95.

27. Koura HM, El-Katoury A, Abdallah NI, El-Bassyouni HT, Ayoub DF, Bassioun RI. Bone mineral density in Egyptian children with Mucopolysaccharidoses. Res J Med Sci 2009; 4: 100-6.

28. Binkovitz LA, Henwood MJ, Sparke P. Pediatric dual-energy X-ray absorptiometry: technique, interpretation, and clinical applications. Semin Nucl Med 2007; 37: 303-13.

29. Saywer AJ, Bachrach LK, Fung EB. Bone densitometry in growing patients. Guidelines for clinical practice. Totowa, NJ: Humana Press 2007. 